\title{
Metschnikowia cerradonensis sp. nov., a yeast species isolated from ephemeral flowers and their nitidulid beetles in Brazil
}

\author{
Carlos A. Rosa, ${ }^{1}$ Marc-André Lachance, ${ }^{2}$ Lia C. R. S. Teixeira, ${ }^{1}$ \\ Raphael S. Pimenta ${ }^{3}$ and Paula B. Morais ${ }^{3}$ \\ ${ }^{1}$ Departamento de Microbiologia, ICB, C.P. 486, Universidade Federal de Minas Gerais, Belo \\ Horizonte, MG, 31270-901, Brazil \\ ${ }^{2}$ Department of Biology, University of Western Ontario, London, Ontario N6A 5B7, Canada \\ ${ }^{3}$ Laboratório de Microbiologia Ambiental e Biologia, Campus Universitário de Palmas, Fundação \\ Universidade Federal do Tocantins, Palmas, Tocantins, 77010-154, Brazil
}

Correspondence Marc-André Lachance lachance@uwo.ca
The large-spored group of the genus Metschnikowia forms a subclade with eight recognized teleomorphic species and the anamorphic species Candida ipomoeae (Lachance et al., 2005). The distribution of most of the taxa is regional, suggesting that they arose in time through allopatric speciation (Marinoni \& Lachance, 2004). Metschnikowia hawaiiensis is associated with the nitidulid beetle Prosopeus subaeneus, which is endemic to the island of Hawai' $\mathrm{i}$, supporting the view that this yeast has speciated in that region (Lachance et al., 1990, 2005). Similarly, Metschnikowia hamakuensis, Metschnikowia kamakouana and Metschnikowia mauinuiana are associated with endemic nitidulid beetles living on various endemic plants on three Hawaiian islands (Lachance et al., 2005). The habitat of Metschnikowia lochheadii and Metschnikowia santaceciliae is in beetles of the genus Conotelus and other insects associated with flowers of Ipomoea (morning glory) species in northwestern Guanacaste Province, Costa Rica (Lachance et al., 2001, 2003). M. lochheadii is also present in insects found in various flowers on the Hawaiian Islands, where it appears to have been introduced. Metschnikowia borealis is restricted to eastern North America, where it is also associated with

The GenBank/EMBL/DDBJ accession numbers for the sequences reported in this paper are D0641236-DQ641243.

The Mycobank accession number for Metschnikowia cerradonensis sp. nov. is MB510051 (http://www.mycobank.org).
Conotelus species and Convolvulaceae flowers (Lachance et al., 1998; Marinoni \& Lachance, 2004). Metschnikowia continentalis was isolated from Ipomoea flowers and species of the genus Conotelus in Brazil (Lachance et al., 1998), where it has a widespread distribution (C. A. Rosa, unpublished results). Candida ipomoeae is an asexual relative of all these species associated with Conotelus beetles and is found in abundance in all regions where Conotelus species occur, except for localities near the Great Lakes area and northward (Marinoni \& Lachance, 2004).

During a study of the yeasts associated with ephemeral flowers in northern Brazil, several strains of a yeast producing large acicular ascospores were isolated from a site in the Cerrado ecosystem. Mating experiments showed that this yeast was capable of mating with $M$. continentalis. However, ascospores were rarely formed. This and other mating results, in combination with an analysis of rDNA sequences, demonstrated that these isolates represent a novel species in the large-spored group of the genus Metschnikowia. The name proposed for this species is Metschnikowia cerradonensis sp. nov.

\section{Strain collection and characterization}

Details of the strains considered in this study are given in Table 1. Collections were made in 2003 and 2005. Flowers of Ipomoea carnea and associated beetles were collected from 
Table 1. Details of strains of Metschnikowia cerradonensis sp. nov. isolated in this study

UFMG, Universidade Federal de Minas Gerais, Brazil.

\begin{tabular}{|lcl|}
\hline Strain & Mating type & \multicolumn{1}{c|}{ Source } \\
\hline UFMG 03-T67.1 & $\mathrm{h}^{\mathrm{T}}$ & Conotelus beetle \\
UFMG 03-T68.1 (allotype) & $\mathrm{h}^{-}$ & Conotelus beetle \\
UFMG 03-T62.1 & $\mathrm{h}^{+}$ & Ipomoea carnea flower \\
UFMG 03-T64.1 & $\mathrm{h}^{-}$ & Ipomoea carnea flower \\
UFMG 03-T64.2 & $\mathrm{h}^{+}$ & Ipomoea carnea flower \\
UFMG 03-T215.2 & $\mathrm{h}^{+}$ & Conotelus beetle \\
UFMG 03-T216.2 & $\mathrm{h}^{+}$ & Conotelus beetle \\
UFMG 05-T332.2 & $\mathrm{h}^{-}$ & Conotelus beetle \\
UFMG 05-T333 & $\mathrm{h}^{-}$ & Conotelus beetle \\
UFMG 05-T334.1 & $\mathrm{h}^{+}$ & Conotelus beetle \\
UFMG 05-T338.1 & $\mathrm{h}^{+}$ & Ipomoea carnea flower \\
UFMG 05-T339.1 & $\mathrm{h}^{-}$ & Ipomoea carnea flower \\
\hline
\end{tabular}

the margins of a small lake ('fervedouro') in the city of São Felix do Tocantins, Jalapão, Brazil, and from several streets and public gardens in the city. Other isolates were retrieved from flowers of Ipomoea species in two forest fragments ('Ipucas') of the Lago Verde estate, in the flooded plains of the Araguaia River, as well as at the entrance of the Ecological Reserve of Canguçu, near the Javaés River. These areas are all found within the Brazilian Cerrado ecosystem of Tocantins State. The nectary region of the Ipomoea flowers was scraped gently with a sterile loop and streak-inoculated onto YM agar $(1.0 \%$ glucose, $0.5 \%$ peptone, $0.3 \%$ malt extract, $0.3 \%$ yeast extract, $2.0 \%$ agar) containing $100 \mathrm{mg}$ chloramphenicol $\mathrm{l}^{-1}$. Conotelus beetles visiting the flowers were placed on YM agar plates and kept for 10-15 min before being removed. Material deposited by the insects was spread evenly with a sterile loop. Representative yeast colonies were purified and maintained on YM slants or in liquid nitrogen in the yeast collections of the Universidade Federal de Minas Gerais (UFMG) or the University of Western Ontario (UWOPS). The yeasts were characterized using standard methods (Yarrow, 1998). Identities were verified using the keys of Kurtzman \& Fell (1998).

Delineation and identification of heterothallic, haplontic Metschnikowia species are derived from mating reactions. Active cultures were mixed in pairs on yeast carbon base (Difco) supplemented with $0.01 \%$ ammonium sulfate, incubated at $22{ }^{\circ} \mathrm{C}$, and examined periodically for the formation of zygotes, asci or ascospores.

The sequence of the complete rDNA repeating unit was determined by PCR amplification using the following forward ( $\mathrm{f}$ ) and reverse ( $\mathrm{r}$ ) primers, listed in order of their occurrence in the sequence: MetETS2r (5'ACCTCCGGGTCCCAAAATTTGCAT3'), IG2r (5'GGCTTAATCTTTGAGACAAGC3'), MetETS3f (5'ATTTATCGCCCAAGTCTCGGGATG3'), SSU1f (5'CTGGTTGATCCTGCCAGTAGTCATA3'), SSU6r (5'AGCTGGAATTACCGCGGCTGCT3'), SSU3f (5'TGGAGGGCAAGTCTGGTGCCA3'),
SSU4r (5'AACTAAGAACGGCCATGCACCA3'), SSU2r (5'ATGATCCTTCCGCAGGTTCAC3'), IT1f (5'TAGGTGAACCTGCGGAAGGATCAT3'), IT2r (5'CTTTTCCTCCGCTTATTGATATGC3'), NL1f (5'GCATATCAATAAGCGGAGGAAAAG3'), NL4r (5'GGTCCGTGTTTCAAGACGG3'), LSU3f (5'CGTCTTGAAACACGGACCAAG3'), LSU5f (5'TAGCCCTGAAAATGGATGGCGCT3'), LSU4r (5'CTCCCACTTATTCTACACCC3'), LSU2r (5'GATCGTAACAACAAGGCTACTC3'), IG1f (5'CGTGAGACAGGTTAGTTTTACCC3') and MetIGSIf (5'CCAATGTTCGAAGATTTGCTTTGGC3'). Sequencing templates were amplified directly from whole cells as described by Marinoni \& Lachance (2004). Amplified DNA was concentrated and cleaned on QIAquick PCR columns (Qiagen) and sequenced in an ABI sequencer at the John P. Robarts Research Institute (London, Ontario, Canada). The sequences were assembled, edited and aligned with the program DNAMAN version 4.1 (Lynnon BioSoft), which makes use of the CLUSTAL algorithm (Thompson et al., 1994). The program SPLITSTREE 4 (version 4.3; Huson \& Bryant, 2006) was used to generate a split decomposition tree. A satisfactory alignment of a large portion of the intergenic spacer region was not possible owing to the abundance of internal repeats of various sizes. Therefore, gapped positions were excluded, such that 6076 nucleotide positions out of 7447 were retained.

Two authentic strains of $M$. continentalis and five strains of M. cerradonensis sp. nov. were used for PCR fingerprinting. DNA templates were prepared as described by de Barros Lopes et al. (1998). The primer EI1 (5'CTGGCTTGGTGTATGT3') targets intron-splicing sites in hypermutable regions of the Saccharomyces genome. PCR assays were performed as described by the authors. PCR products were analysed by $1 \%$ agarose gel electrophoresis.

\section{Ecology and species relationships}

Strains of M. cerradonensis sp. nov. were isolated from flowers of I. carnea and from Conotelus species collected on the margins of a small lake in São Felix do Tocantins. Morning glory flowers sampled in public gardens and streets of São Felix yielded only basidiomycetous yeasts and Candida azyma. Samples taken in two other areas of the Cerrado, located approximately $300 \mathrm{~km}$ from Jalapão, yielded only $M$. continentalis, suggesting that $M$. cerradonensis might be endemic to the Jalapão region.

The phylogenetic relationships among M. cerradonensis and its relatives are shown in Fig. 1. The use of split decomposition instead of the more usual neighbour-joining or other phylogenetic analysis methods was dictated by the fact that different parts of the rDNA cluster would lead to somewhat contradictory phylogenies. Although such inconsistencies would be flagged by low bootstrap values, alternative branching orders would remain unknown. Split decomposition (Huson \& Bryant, 2006) displays simultaneously the major trends suggested by the sequence data as parallelograms in which the longer sides join the 


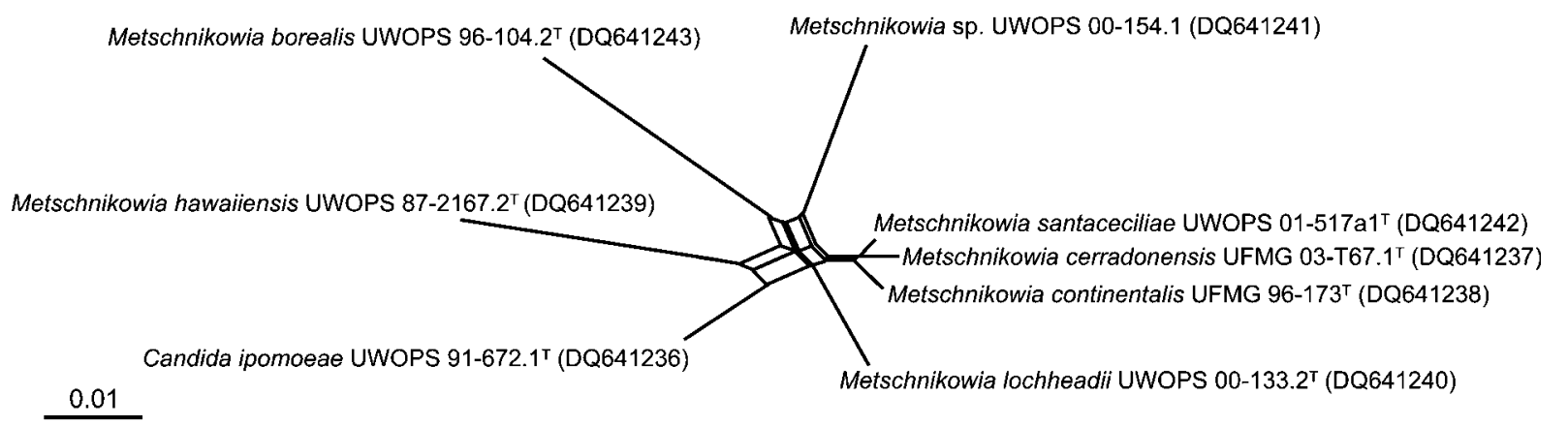

Fig. 1. Split decomposition network of the rDNA sequences of Metschnikowia cerradonensis sp. nov. and related species. Only ungapped positions were used in the analysis. Bar, $1 \%$ sequence divergence.

better supported hierarchy. In the present case (Fig. 1), the clear interpretation is that M. cerradonensis, $M$. santaceciliae and $M$. continentalis are sister species, but that several alternative branching orders are possible among the remaining species. For example, the split decomposition network suggests that Metschnikowia sp. UWOPS 00-154.1 and Candida ipomoeae are almost as likely to be basal members of the subclade containing the novel species as they are to be sister species with $M$. borealis and M. hawaiiensis, respectively. Nonetheless, an affinity of the novel species with M. lochheadii and Metschnikowia sp. UWOPS 00-154.1 is evident.

Analysis of shorter regions of the rDNA unit, for example the popular D1/D2 LSU domains, has led to somewhat different conclusions about some of these species, including the original belief that $M$. continentalis and $M$. borealis should be viewed as varieties of a single species (Lachance et al., 1998), or that M. lochheadii and Candida ipomoeae might represent a teleomorph-anamorph pair (Lachance et al., 2001). Both suggestions were later disproved (Marinoni \& Lachance, 2004). M. cerradonensis differs from $M$. santaceciliae and $M$. continentalis only by two substitutions and 1-2 indels in the D2 domain and from $M$. santaceciliae by one substitution in the D1 domain. The internal transcribed spacer region of $M$. cerradonensis contains several substitutions and is 21 and $30 \mathrm{nt}$ longer than that in $M$. santaceciliae and $M$. continentalis, respectively. Differences from $M$. lochheadii are slightly greater. The species boundaries were established by mixing strains of the above four species plus Metschnikowia sp. UWOPS 00-154.1 in every possible combination. Rare single-spored asci were observed on occasion in crosses involving $M$. cerradonensis, $M$. santaceciliae and $M$. continentalis. By contrast, intraspecific crosses gave rise to abundant two-spored asci. Sterile asci are formed in extraspecific mixtures of complementary mating types of all members of the large-spored subclade.

M. cerradonensis and its most closely related species were indistinguishable based on growth test profiles. For this reason, PCR amplification with the intron-splicing-site primer was useful in distinguishing $M$. continentalis from $M$. cerradonensis, as both species might possibly occur in the same samples. The two species showed distinct PCR fingerprint profiles (Fig. 2). Conspecific isolates generally produce similar banding profiles (de Barros Lopes et al., 1998; Carreiro et al., 2004; Pimenta et al., 2005). This was the case here, although some variation was detectable within the two species. Ascospore formation in mixtures with the mating types of authentic strains or rDNA sequencing are recommended for definitive identification.

\section{Latin diagnosis of Metschnikowia cerradonensis Rosa, Lachance et Morais sp. nov.}

In medio YM post dies tres cellulae singulae, binae, aut in catenis brevis, globosae aut ovoidae $(2-4 \times 3-6 \mu \mathrm{m})$, aliquando cum tubis longibus. Cultura in agaro malti post dies 14 infimoconvexa, glabra, candida et butyrosa aut coriacea. In agaro farinae Zea mays post dies 14 pseudomycelium formatur. Post dies unus, cellulae stirpum interfertilium mixtarum in agaro carbonis fundamento tubi junctionis formantur. Post dies tres, magni asci cylindrati possunt videri. Asci stabiles sunt. Ascosporae aculeatae

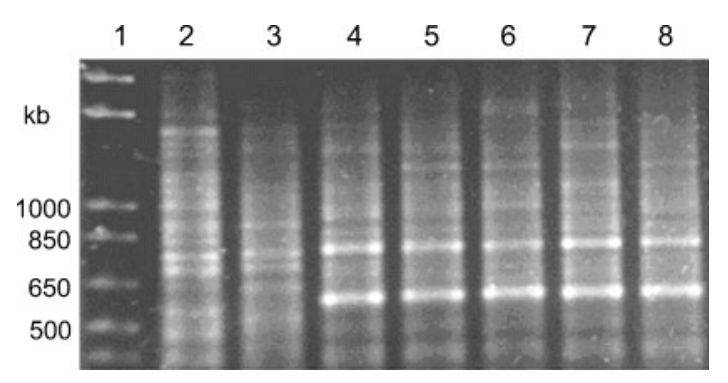

Fig. 2. PCR fingerprints of Metschnikowia continentalis and Metschnikowia cerradonensis sp. nov. strains obtained using the primer El1. Lanes: 1, $1 \mathrm{~kb}$ Plus DNA ladder; 2, M. continentalis UFMG 05-T65 $\left(\mathrm{h}^{+}\right) ; 3, M$. continentalis UFMG 05-T13 $\left(\mathrm{h}^{-}\right) ; 4$, M. cerradonensis UFMG 03-T68.1 $\left(\mathrm{h}^{-}\right) ; 5, \mathrm{M}$. cerradonensis UFMG 03-T67.1 $1^{\top}\left(\mathrm{h}^{+}\right) ; 6, \quad$. cerradonensis UFMG 05-T338.1 $\left(\mathrm{h}^{+}\right) ; 7$, M. cerradonensis UFMG 05-T332.2 $\left(\mathrm{h}^{-}\right) ; 8$, M. cerradonensis UFMG 05-T334.1 $\left(\mathrm{h}^{+}\right)$. 
(1.3-1.6 $\times 60-150 \mu \mathrm{m})$. Glucosum fermentatur. Glucosum, sucrosum, galactosum, trehalosum, maltosum, melezitosum, cellobiosum, salicinum (exigue), L-sorbosum, D-xylosum, glycerolum (lente et exigue), ribitolum (lente), xylitolum, mannitolum, glucitolum, acidum succinicum, acidum citricum (lente), acidum gluconicum, $N$-acetylglucosaminum, ethylacetas (lente) et hexadecanum assimilantur, at non inulinum, raffinosum, melibiosum, lactosum, methyl-5-Dglucosidum, amylum solubile, L-rhamnosum, L-arabinosum, D-arabinosum, D-ribosum, methanolum, 2-propanolum, ethanolum, erythritolum, galactitolum, meso-inositolum, acidum lacticum, glucosaminum nec acetonum. Ethylaminum, lysinum et cadaverinum assimilantur at non natrium nitricum nec natrium nitrosum. Ad crescentiam vitamina externa necessaria sunt. Augmentum in $34^{\circ} \mathrm{C}$, at non $35^{\circ} \mathrm{C}$.

Habitat Conotelus sp. et Ipomoea carnea in Brazil. Typus: UFMG 03-T67.1 ${ }^{\mathrm{T}}\left(\mathrm{h}^{+}\right)$. Allotypus: UFMG 03-T68.1 $\left(\mathrm{h}^{-}\right)$. In collectione zymotica Centraalbureau voor Schimmelcultures, Trajectum ad Rhenum, sub no. CBS 10409 et CBS 10410 depositae sunt.

\section{Description of Metschnikowia cerradonensis Rosa, Lachance \& Morais sp. nov.}

Metschnikowia cerradonensis (cer.ra.do.nen'sis. L. nom. sing. $m$. adj. cerradonensis of Cerrado, referring to the Cerrado ecosystem, where all known strains of the species were recovered).

On YM agar after 3 days at $25^{\circ} \mathrm{C}$, cells are spherical to ovoidal, occur singly, in parent-bud pairs or in short chains, and measure 2-4 $\times 3-6 \mu \mathrm{m}$. Highly refringent cells as well as very long germ tubes are observed on occasion. After 2 weeks, colonies are of low convexity or are convex, glossy, white, small to medium sized, butyrous or leathery owing to intertwined tubes. In Dalmau plate cultures on cornmeal agar after 2 weeks, abundant pseudohyphae are formed in some, but not all, cultures. On yeast carbon base agar at $22^{\circ} \mathrm{C}$, mixtures of cells of complementary mating types give rise to zygotes and asci after 12-24 h. After 3 days, mature asci containing two acicular ascospores $(1.3-1.6 \times 40-150 \mu \mathrm{m})$ are formed in a persistent ascus that retains more or less conspicuous vestiges of the conjugated parent cells (Fig. 3). Gas production from glucose begins after 1-2 days. Galactose, sucrose, maltose and trehalose are not fermented. Glucose, sucrose, galactose, trehalose, maltose, melezitose, cellobiose, salicin (weak), Lsorbose, D-xylose, glycerol (slow and weak), ribitol (slow), xylitol, mannitol, glucitol, succinic acid, citric acid (slow), gluconic acid, $N$-acetylglucosamine, ethyl acetate and hexadecane are assimilated. No growth occurs on inulin, raffinose, melibiose, lactose, soluble starch, L-rhamnose, Larabinose, D-arabinose, D-ribose, methanol, 2-propanol, ethanol, erythritol, galactitol, myo-inositol, lactic acid, Dglucosamine or acetone. Assimilates the following nitrogen compounds: lysine, ethylamine- $\mathrm{HCl}$ and cadaverine; but negative in tests for nitrate and nitrite. No growth in

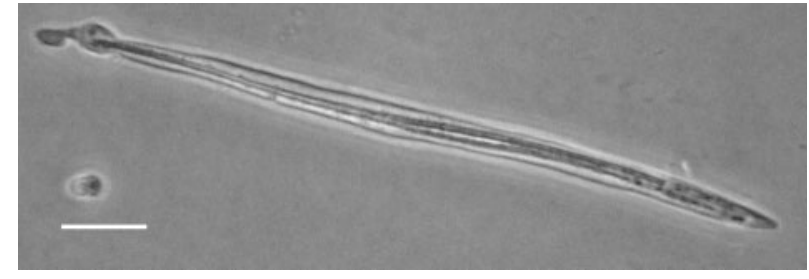

Fig. 3. Phase-contrast micrograph of a mature ascus with two acicular ascospores of Metschnikowia cerradonensis sp. nov. on yeast carbon base agar with $0.01 \%$ ammonium sulfate after 2 weeks at $17^{\circ} \mathrm{C}$. Bar, $10 \mu \mathrm{m}$.

vitamin-free medium, but growth is observed in aminoacid-free medium. Grows at $34^{\circ} \mathrm{C}$, but not at $35^{\circ} \mathrm{C}$. Growth on YM agar with $10 \%$ sodium chloride is slow. No growth in $50 \%$ glucose/yeast extract $(0.5 \%)$. Starch-like compounds are not produced. No growth in $100 \mu \mathrm{g}$ cycloheximide $\mathrm{ml}^{-1}$. Urease-negative. Diazonium blue B reaction is negative.

The type strain, UFMG 03-T67.1 $1^{\mathrm{T}} \quad\left(\mathrm{h}^{+}\right) \quad(=\mathrm{CBS}$ $10409^{\mathrm{T}}=$ NRRL Y-48067 $7^{\mathrm{T}}$, was recovered from Conotelus beetles (Coleoptera: Nitidulidae) associated with flowers of Ipomoea carnea growing in the margins of a small lake of the Jalapão area in the city of São Felix do Tocantins, Tocantins State, Brazil. The designated allotype, UFMG 03-T68.1 $\left(\mathrm{h}^{-}\right)$ $(=$ CBS $10410=$ NRRL Y-48068), was recovered from Conotelus beetles.

\section{Acknowledgements}

This work was funded by Programa Norte de Pesquisas e PósGraduação do Conselho Nacional de Desenvolvimento Científico e Tecnológico of Brazil (PNOPG-CNPq), CNPq - Brazil (process no. 477528/03-1), Fundação do Amparo a Pesquisa do Estado de Minas Gerais (FAPEMIG, process no. CBB - 378/04) and the Natural Science and Engineering Research Council of Canada (M.-A. L.).

\section{References}

Carreiro, S. C., Pagnocca, F. C., Bacci, M., Jr, Lachance, M. A., Bueno, O. C., Hebling, M. J., Ruivo, C. C. C. \& Rosa, C. A. (2004). Sympodiomyces attinorum sp. nov., a yeast species associated with nests of the leaf-cutting ant Atta sexdens. Int J Syst Evol Microbiol 54, 1891-1894.

de Barros Lopes, M., Soden, A., Martens, A. L., Henschke, P. A. \& Langridge, P. (1998). Differentiation and species identification of yeasts using PCR. Int J Syst Bacteriol 48, 279-286.

Huson, D. H. \& Bryant, D. (2006). Application of phylogenetic networks in evolutionary studies. Mol Biol Evol 23, 254-267.

Kurtzman, C. P. \& Fell, J. W. (1998). The Yeasts, a Taxonomic Study. Amsterdam: Elsevier.

Lachance, M. A., Starmer, W. T. \& Phaff, H. J. (1990). Metschnikowia hawaiiensis sp. nov., a heterothallic haploid yeast from Hawaiian morning glory and associated drosophilids. Int J Syst Bacteriol 40, $415-420$. 
Lachance, M. A., Rosa, C. A., Starmer, W. T., Schlag-Edler, B., Barker, J. S. F. \& Bowles, J. M. (1998). Metschnikowia continentalis var. continentalis, Metschnikowia continentalis var. borealis, and Metschnikowia hibisci, new heterothallic haploid yeasts from ephemeral flowers and associated insects. Can J Microbiol 44, 279-288.

Lachance, M. A., Bowles, J. M., Kwon, S., Marinoni, G., Starmer, W. T. \& Janzen, D. H. (2001). Metschnikowia lochheadii and Metschnikowia drosophilae, two new yeast species isolated from insects associated with flowers. Can J Microbiol 47, 103-109.

Lachance, M. A., Bowles, J. M. \& Starmer, W. T. (2003). Metschnikowia santaceciliae, Candida hawaiiana, and Candida kipukae, three new yeast species associated with insects of tropical morning glory. FEMS Yeast Res 3, 97-103.

Lachance, M. A., Ewing, C. P., Bowles, J. M. \& Starmer, W. T. (2005). Metschnikowia hamakuensis sp. nov., Metschnikowia kamakouna sp. nov. and Metschnikowia mauinuiana sp. nov., three endemic yeasts from Hawaiian nitidulid beetles. Int J Syst Evol Microbiol 55, 1369-1377.

Marinoni, G. \& Lachance, M. A. (2004). Speciation in the largespored Metschnikowia clade and establishment of a new species, Metschnikowia borealis comb. nov. FEMS Yeast Res 4, 587-596.

Pimenta, R. S., Alves, P. D. D., Corrêa, A., Jr, Lachance, M. A., Prasad, G. S., Rajaram, Sinha, B. R. R. P. \& Rosa, C. A. (2005). Geotrichum silvicola sp. nov., a novel asexual arthroconidial yeast species related to the genus Galactomyces. Int J Syst Evol Microbiol 55, 497-501.

Thompson, J. D., Higgins, D. G. \& Gibson, T. J. (1994). CLUSTAL W: improving the sensitivity of progressive multiple sequence alignment through sequence weighting, position-specific gap penalties and weight matrix choice. Nucleic Acids Res 22, 4673-4680.

Yarrow, D. (1998). Methods for the isolation and identification of yeasts. In The Yeasts, a Taxonomic Study, 4th edn, pp. 77-100. Edited by C. P. Kurtzman \& J. W. Fell. Amsterdam: Elsevier. 